\title{
THE BIM-FOR-RAIL OPPORTUNITY
}

\author{
MAREK SUCHOCKI \\ Autodesk Ltd., UK
}

\begin{abstract}
The rail industry is one of the oldest and most mature engineering sectors. However, Building Information Modelling (BIM) adoption in the sector has been relatively slow, typically focused on individual projects where the participants involved have recognised the opportunity BIM presents to improve specific activities rather than meeting client set requirements. A significant global investment pipeline exists in the rail sector, which at the same time is facing recruitment challenges in the industry where a relatively mature workforce and perceived lack of innovation discourage new entrants. The adoption of new technologies can help meet the growing demand and offset the difficulty of attracting sufficient resources to deliver the work. By deploying readily available BIM and associated technologies, significant workflow improvements can be achieved in rail engineering whilst still satisfying current contractual requirements such as the rapid creation of $2 \mathrm{D}$ drawings comprising cross-sections, plans, elevations and details direct from the model that are automatically updated when a model is changed.
\end{abstract}

Keywords: BIM, rail, innovation, visualisation, recruitment.

\section{INTRODUCTION}

Despite a small slowdown, the global railway market is showing solid growth and is predicted to grow by $2.3 \%$ a year until 2020 [1]. The market value is worth $\$ 169 \mathrm{bn}$ and in 2015 five countries were responsible for $50 \%$ of the total: China, the United States, Russia, Germany and France. This provides significant opportunities for the global rail supply chain to deliver services locally and internationally.

Meeting the sustained demand for global rail investment, nevertheless presents numerous challenges to the rail industry, which is one of the oldest and most mature engineering sectors. It has a long tradition of engineering excellence, standardisation, safety and professionalism. However, its legacy is also one of its constraints, in that standard practice and reliance on the safety case can be used as an excuse to avoid change or invest in innovation. The industry also has an age profile that includes many employees who are in the late stages of their careers ( $\sim 24 \%$ over 50 [2]) and may be less willing to change processes or technologies.

The productivity and process improvements that Building Information Modelling (BIM) offers are undeniable [3] across all sectors of the construction industry including civil engineering [4]. Its take up in the rail sector has however been focused on individual projects where the participants involved have recognised the opportunity BIM presents to improve specific activities.

Part of the challenge is that, for example, in the UK Network Rail's engineering assurance procedures require submission of $2 \mathrm{D}$ drawings to prescribed CAD standards, with little clarity on if delivery of a model as an alternative is acceptable [5]. This results in doubling of effort by design teams who prepare BIM models but then need to ensure they can still create the prescribed 2D deliverables. This is not an insurmountable challenge because deploying the best available technologies permit the rapid creation of $2 \mathrm{D}$ drawings comprising cross-sections, plans, elevations and details direct from the model and automatically updated when there is a change to the model. However, legacy practice, using 
known incumbent solutions, frequently separates the modelling from the drawing generation that introduces a productivity penalty and risk of inconsistency between the models and drawings.

\section{WHERE DO YOU START?}

A major barrier to BIM adoption is a misunderstanding of the whole life cycle of an engineering process. Designers and constructors are happy to work on improvements to their individual procedures and contracted obligations but without exploring the wider workflow to determine if a larger scale change across multiple phases and disciplines can deliver more significant benefits.

When looking at the complete lifecycle of a scheme, the area of potentially greatest opportunity to impact outcomes is in the early planning and conceptualising phases. The Network Rail Governance of Railway Investment Projects (GRIP) process is a comprehensive eight stage framework characterised by increasing levels of scope and cost certainty as projects develop through their life-cycle [6]: defining outputs at GRIP1; option selection at GRIP3; detailed design at GRIP5; and construction, testing and commissioning at GRIP6. It is the GRIP 1 to 3 phases that could benefit most from a radical alteration in the methods adopted to assess schemes.

Network Rail state [7] that at phase 2, as part of a project's business case development, they need to establish:

- a sustainable funding route for the project, including risk management;

- what, if any, adverse impact the scheme will have on network capacity, and options to mitigate this; and

- what are the interface risks with Operations, Maintenance and Renewal (OM\&R) activities, that may include:

○ the requirements for the safe accommodation of works;

o the needs of other users of the network;

- avoiding conflict with the existing rights of other users; and

○ the need to verify that they are not placed at undue risk of breaching their stewardship obligations as set out in the network licence.

BIM technologies coupled with improved use of legacy asset data, geospatial data, laser and photogrammetric scan data as well as ground survey information can fully support the requirements of the GRIP2 phase by providing a comprehensive understanding of the as-is environment. This information can be used concurrently to determine new route options, proposed new structures or buildings, plan temporary works and access, and develop detailed visualisations and simulations to forecast the build process.

It is rare that the rich available data is used at these stages due to legacy systems being fragmented and unable to effectively use multiple data formats. Moreover, departmental segregation typically results in the stewards of asset data or the geospatial systems not communicating what stored information is readily available to designers and planners who are exploring a new scheme. This results in re-surveying the area under inspection rather than starting with a potentially accurate and rich set of existing data.

\section{IMPROVING PLANNING}

An improved approach to satisfying the early stage planning and conceptual design requirements such as GRIP 2 would be to adopt a BIM enabled workflow. Technologies that permit data aggregation and concurrent review need to be introduced to create an understanding of the as-is situation. 


\subsection{Existing conditions acquisition}

Where legacy data is incomplete or poor, the existing conditions need to be surveyed. This is possible using traditional surveying techniques such as total stations, physical measurement, and photography but can today be greatly enhanced and accelerated through the adoption of technologies such as ground laser scanning and aerial drone photography with photogrammetric data-processing. The resulting point-clouds from these rapid surveys can now be included as-is in aggregated models or part processed to remove unwanted data such as vegetation or obstructions, select identified assets, determine vertices and planes of physical objects or analysed to create new topographic surfaces of an area under inspection.

Implementing remote sensing no longer requires specialist skills. Integrated workflows are available from the most advanced providers where for example drone to photogrammetry can be automated where the operator simply describes a flight path and all other process steps are automatic e.g. calculating the required number and location of photos, take-off and landing, upload of images to cloud service and return of a computed point cloud (Fig. 1).

The below ground information is also often ignored but is critical to civil engineering design. Outputs from ground-penetrating radar surveys, boreholes, sub-surface asset records and also data provided by agencies, such as the British Geological Survey (BGS), can also be incorporated to show accurate positioning of below ground assets or to identify the geological sub-strata converted into 3 dimensional planes or solids. The utilisation of subsurface data for BIM is being explored in an Innovate UK funded research project [8] led by Keynetix and supported by BGS, Atkins and Autodesk.

\subsection{Conceptual design and options analysis}

Determining suitable concepts for a route is often an exercise based solely on engineering intuition or considering basic known constraints such as land ownership. Geospatial mapping tools are a commonly implemented technology to show in two dimensions existing built and natural features, including the rail assets that permit an understanding of the as-is situation in order to make judgements on potential solutions for proposed investments, which may be supplemented by the aforementioned ground surveys, photographs and historic $2 \mathrm{D}$ drawings.

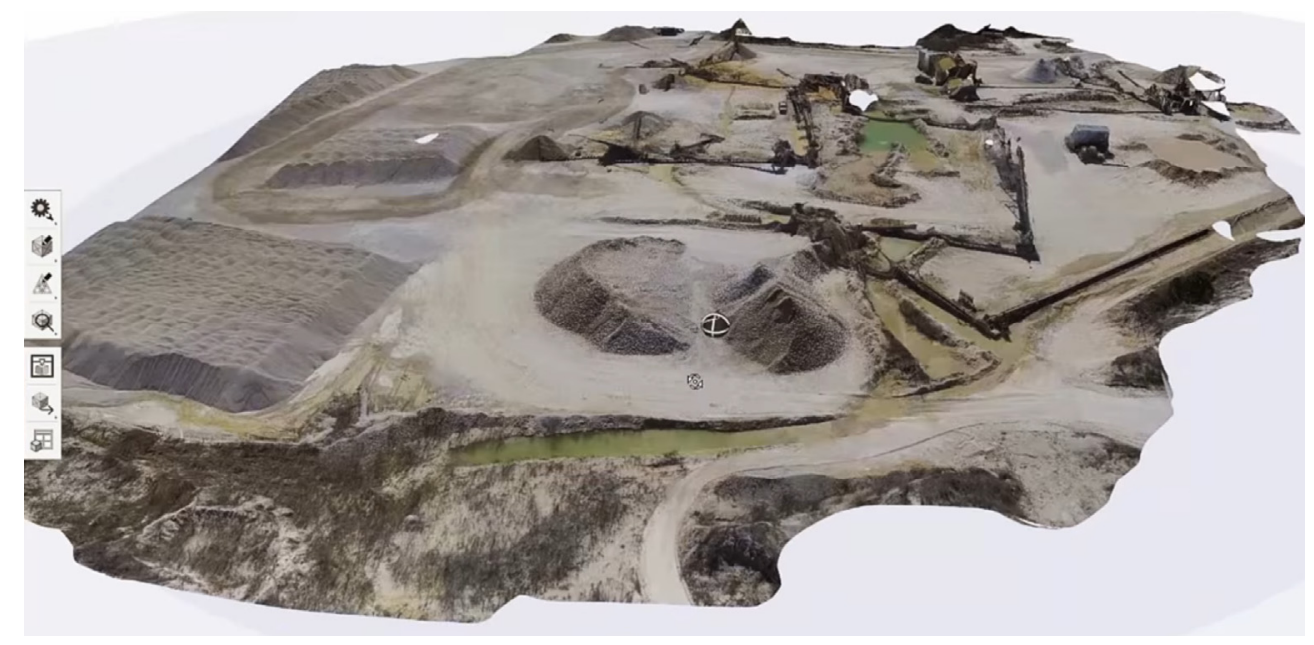

Figure 1: Site surveyed using 3D Robotics to Autodesk ${ }^{\circledR}$ Recap ${ }^{\circledR}$ automated workflow. 
The improved digital data available to commence planning schemes described in the previous section enables entirely new methods [9] to be adopted to visualise the existing conditions, understand the impact of constraints, and to evaluate design alternatives. Fig. 2 shows how Mott MacDonald developed a proposal for a level crossing replacement in Barnby using aggregated spatial data to create three-dimensional representation of the existing rural and urban conditions with a conceptual overpass option evaluated in a single model environment.

\subsubsection{Conceptual planning based on historic knowledge}

The quality of options evaluated can further be enhanced by introducing knowledge-based techniques, where historic data related to performance or cost of infrastructure assets is used to allow options to be iterated and priced from the outset to arrive at an optimised set of alternatives from a very early stage.

LightOS, a small independent developer, who have recently produced a solution that leverages historic asset data and costs to predictively design rail schemes based on the existing topography and typical rail asset data. The LightOS solution predetermines the type and number of standard assets such as bridges, cuttings and embankments that will be required and then integrates into BIM tools including Autodesk's Civil $3 \mathrm{D}^{\circledR}$ and Revit ${ }^{\circledR}$ to fully develop early-stage solutions prior to export into the CostOS ${ }^{\circledR}$ costing platform to deliver well developed cost plans, with high confidence, from the outset.

\subsubsection{Generative design}

It is also possible to leverage advanced generative design tools [10] to support the design team in their decision making. Whilst these technologies lend themselves more typically to manufactured elements, the same approach can be applied to optimising structures and other assets in terms of their performance e.g. reducing wind impact, energy consumption, or structural behaviour.

When adopting these tools, designers describe constraints and target performance parameters against, which the software can analyse 1000s of alternatives to arrive at the design options that best match as illustrated in Fig. 3 .

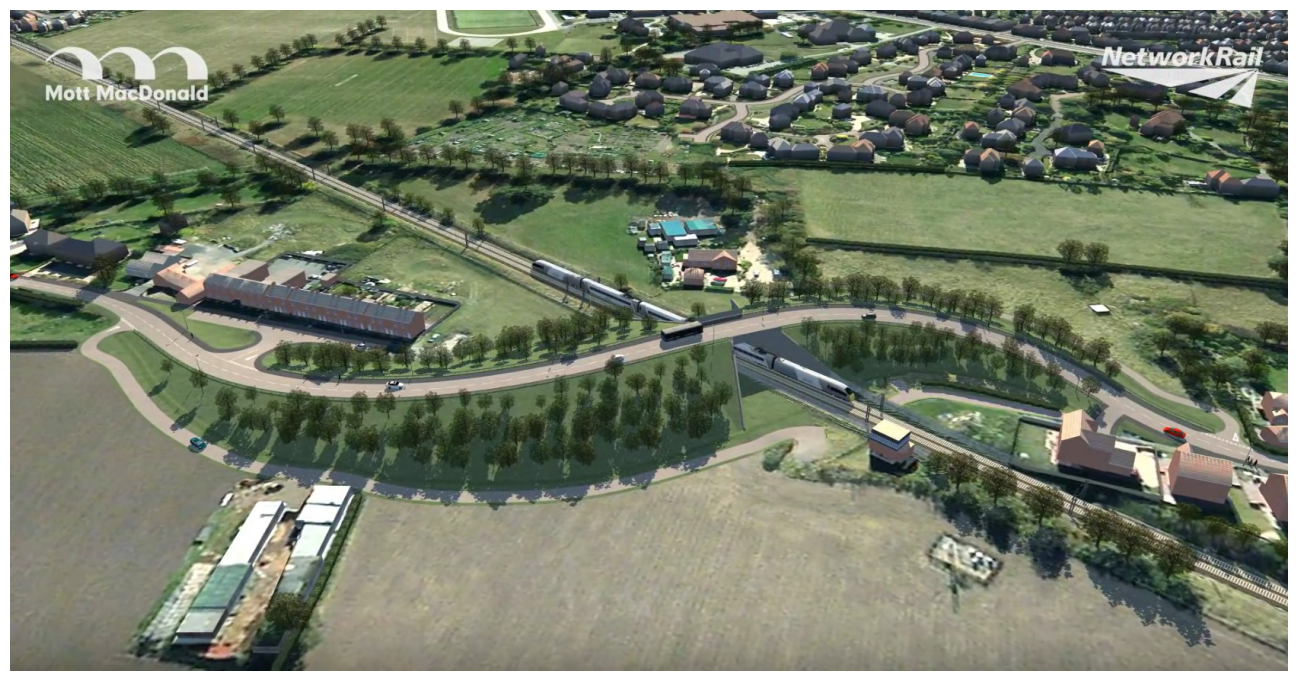

Figure 2: Mott MacDonald proposal for a level crossing replacement in Barnby. 


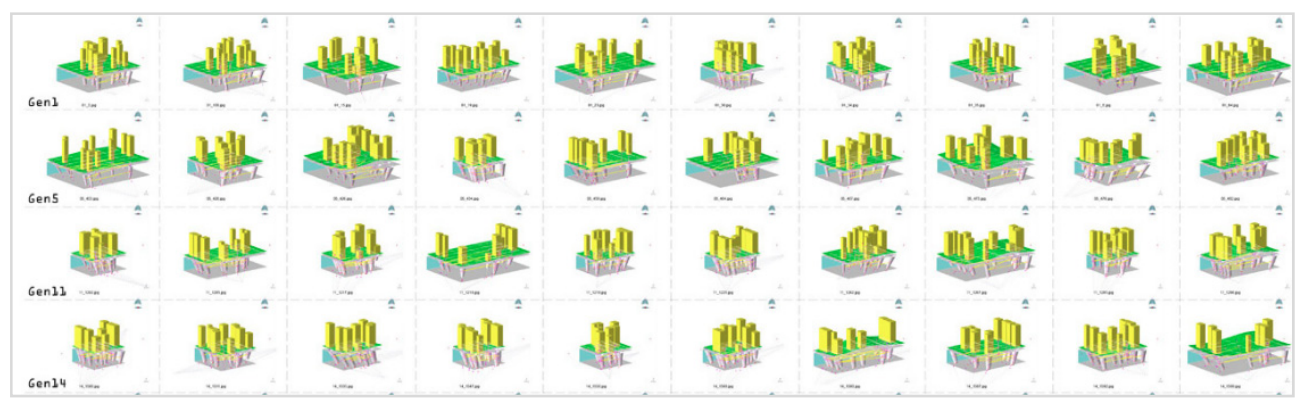

Figure 3: Example of generative design optimising structural design [11].

\section{PREFERRED OPTION SELECTION}

Once preferred options have been identified, fully developed designs can be prepared in detailed modelling solutions, which can leverage engineering rules and parametric intelligent objects to fully test the viability of a proposal, coordinated across the various disciplines that relate to an asset. This is particularly important for complex structures such as stations as illustrated in the Autodesk Revit ${ }^{\circledR}$ model by Prota Group of one of 19 Stations on the $22.5 \mathrm{~km}$ Kabataş-Mahmutbey underground Metro Line in Istanbul (Fig. 4).

These fully developed models can also be analysed against numerous performance parameters directly from the source model e.g. structural analysis, environmental analysis, computational fluid dynamics (CFD) or construction sequencing.

Implementing BIM in a fully planned multi-disciplinary workflow can also overcome many inefficiencies in traditional practice. Employing a process management technology such as Autodesk Dynamo ${ }^{\circledR}$, can allow multiple steps in a design process to be synchronised. For example, a rail alignment can be associated to structures such as bridge decks or tunnels that are modelled in disparate tools; if a change is made to the alignment the other designs can automatically move or parametrically change geometry accordingly. Such changes are extremely labour-intensive to manage effectively in legacy processes and are a key source of error due to omissions where a change in alignment is not reflected in all associated assets.

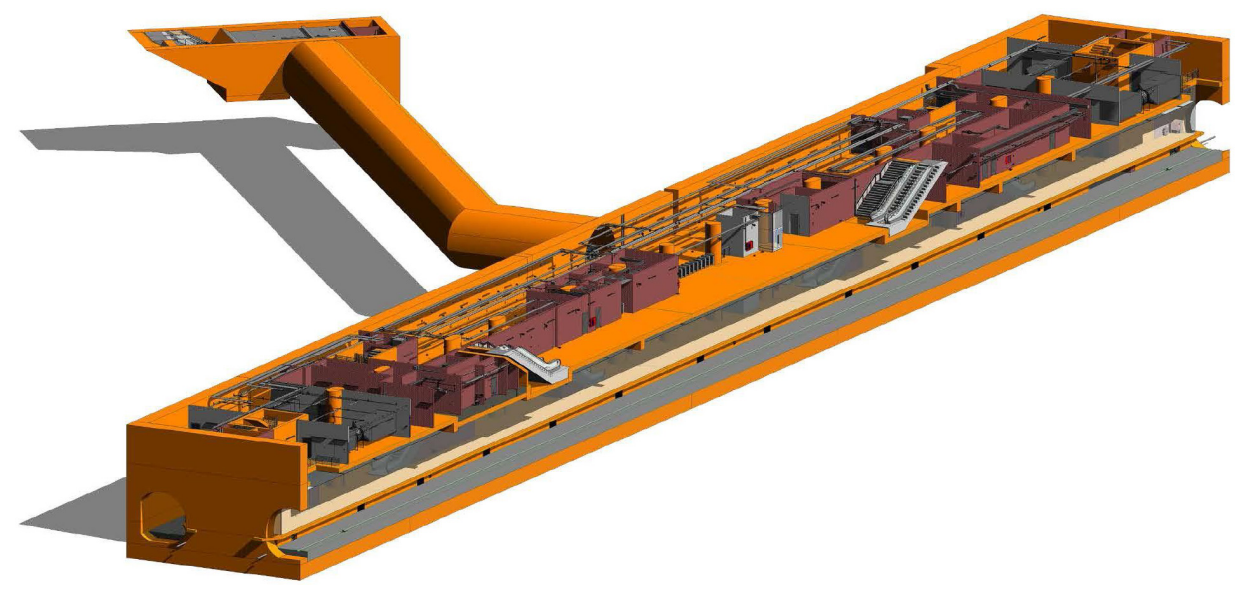

Figure 4: BIM of a station on the Kabataş-Mahmutbey Metro Line in Istanbul. 
Once designs have been finalised, drawings such as 2D plans, elevations and details can be created directly from the approved models. Generating drawings once designs are fully developed ensures errors from omissions or assumptions are reduced and consequently significantly improves process productivity.

Finalised design options can be re-integrated within the full contextual environment developed during concept activities, which can then facilitate further processes to be executed such as planning construction works as shown in Fig. 5. This demonstrates how data is re-used and built upon through the project lifecycle rather than a historic typical approach where preceding phase design information is 'thrown away' with limited re-use.

Models are also not restricted to use by the professional project community. The aggregated models can be exported into gaming or visualisation environments to create immersive models that can be used by the design teams, their clients or other stakeholders. Jeff Mottle of CG Architect has recently stated [12] that the ready availability of Virtual Reality conversion software and headsets mean this approach is liable to be increasingly used and expected.

\section{TECHNOLOGY SELECTION}

Technology selection in the rail sector has also been constrained by traditional thinking and legacy practice. These behaviours develop challenges when adopting BIM related to poor interoperability or unsuitable core technologies. Prioritisation of technology against the scale of investment on a given project is critical and the California High Speed Rail Authority prepared their project business plan [13] to ascertain the anticipated costs by Federal Rail Authority (FRA) standard cost categories. The estimated costs from the business plan for the Initial Operating Section (IOS), which is approximately 300 miles long permitting operation of high-speed rail from Merced to the San Fernando Valley, are shown in Table 1.

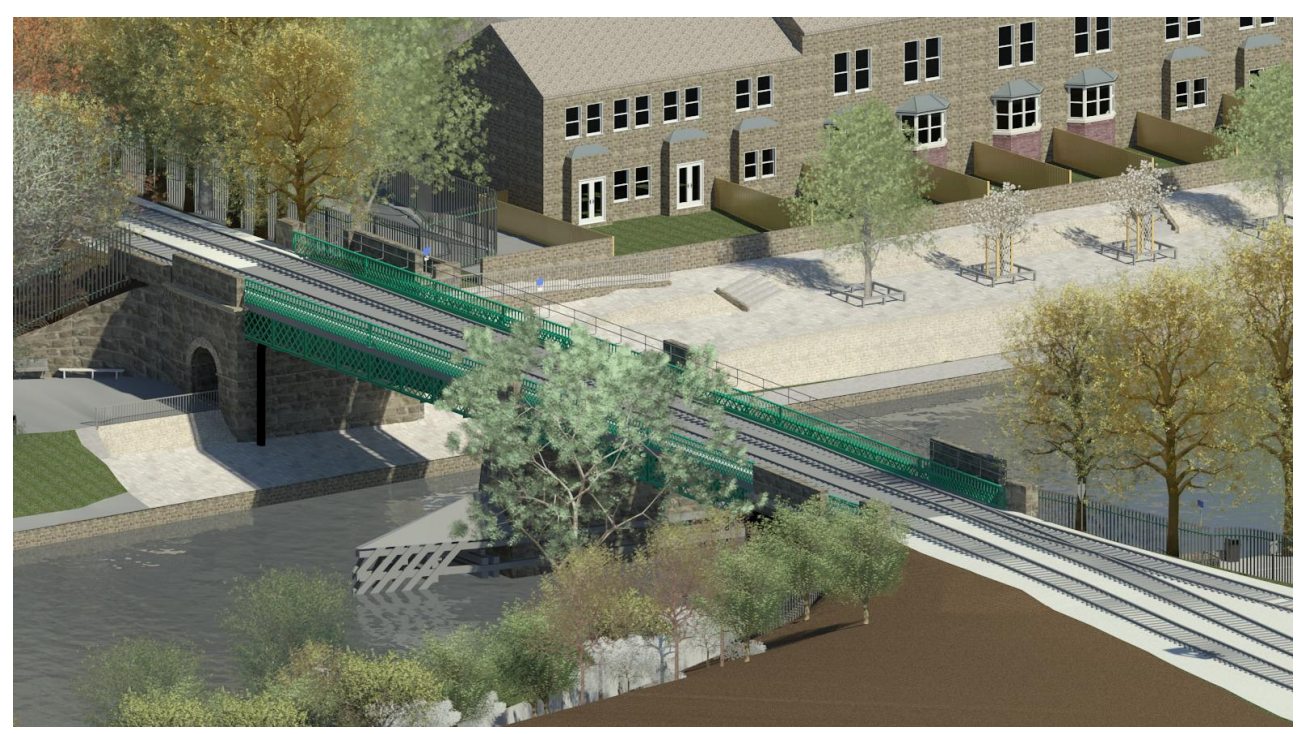

Figure 5: Network Rail aggregated model of proposed bridge in local context, used for evaluating construction methods and constraints such as works site and crane positioning. 
Table 1: Relative costs by asset category of a rail project at 2011 \$ rates (California High Speed Rail cost estimates to construct IOS).

\begin{tabular}{llllll}
\hline Code & FRA standard cost category & $\begin{array}{l}\text { Low-cost } \\
\text { Option } \\
\text { (millions) }\end{array}$ & $\begin{array}{l}\% \text { of } \\
\text { total }\end{array}$ & $\begin{array}{l}\text { High-cost } \\
\text { Option } \\
\text { (millions) }\end{array}$ & $\begin{array}{l}\% \text { of } \\
\text { total }\end{array}$ \\
\hline 10 & Track structures and track & $\$ 14,319$ & 53.3 & $\$ 17,275$ & 55.1 \\
\hline & Civil & $\$ 1470$ & 5.5 & $\$ 1712$ & 5.5 \\
\hline & Structures & $\$ 11,719$ & 43.6 & $\$ 14,298$ & 45.6 \\
\hline & Track & $\$ 1132$ & 4.2 & $\$ 1267$ & 4.0 \\
\hline 20 & Stations, terminals, intermodal & $\$ 618$ & 2.3 & $\$ 618$ & 2.0 \\
\hline 30 & $\begin{array}{l}\text { Support facilities: yards, shops, } \\
\text { administrative buildings }\end{array}$ & $\$ 433$ & 1.6 & $\$ 433$ & 1.4 \\
\hline 40 & $\begin{array}{l}\text { Site work, right-of-way, land, existing } \\
\text { improvements }\end{array}$ & $\$ 4667$ & 17.4 & $\$ 5341$ & 17.0 \\
\hline 50 & Communications and signalling & $\$ 518$ & 1.9 & $\$ 559$ & 1.8 \\
\hline 60 & Electric traction & $\$ 1699$ & 6.3 & $\$ 1830$ & 5.8 \\
\hline 70 & Vehicles & $\$ 871$ & 3.2 & $\$ 871$ & 2.8 \\
\hline 80 & Professional services (applies to & $\$ 2805$ & 10.4 & $\$ 3309$ & 10.6 \\
\hline 90 & Categories 10-60) & & & & \\
\hline 100 & Fnallocated contingency & $\$ 935$ & 3.5 & $\$ 1103$ & 3.5 \\
\hline & Finance charges & $\$-$ & 0 & $\$-$ & 0.0 \\
\hline & Total & $\$ 26,865$ & & $\$ 31,339$ & \\
\hline
\end{tabular}

These estimates highlight that track constitutes less than $5 \%$ of the total cost of a scheme and yet is typically the deciding factor when selecting technologies for a project. Track design should instead be regarded as a critical supporting technology that feeds and integrates with the other assets, which may be of equal or higher total project value such as civil works, structures and buildings.

\section{SUMMARY}

The rail sector globally has struggled to leverage the best available technologies due to a dependence on traditional practices. Other factors such as an over-reliance on the safety case as an excuse rather than driver for change have also deterred process innovation. The growing demand for infrastructure investment globally, coupled with reducing resources to deliver the required workload, has reinforced the need for adoption of new work procedures and technologies.

The range of solutions available to engineers and other designers today is unprecedented, permitting acceleration of context understanding, exploration of options, design development, and ultimately improved decision making. The benefits from adopting technologies go beyond just time and also include better solutions, more engaged stakeholders, dramatically reduced errors during the capital phase of projects and significant improvements during asset use.

The further opportunity to encourage new entrants into the sector by improving its attractiveness is also significant and for rail clients as well as the rail supply chain, should be considered as a primary factor that will help future proof the sector. 


\section{REFERENCES}

[1] The Worldwide Market for Railway Industries study, SCI Verkehr, Germany, 2016.

[2] State of the Nation in Passenger Transport, 2012.

[3] Productivity Benefits of BIM, Building and Construction Productivity Partnership, NZ, 2014.

[4] How BIM improves safety, increases efficiency and reduces operating costs. Global Construction, April 2015.

[5] Engineering Assurance of Building and Civil Engineering Works, Network Rail, UK, Sep. 2012.

[6] Review of Network Rail's SBP Infrastructure Enhancement Proposals for CP5, Nichols, Jun. 2013.

[7] Investing in the Network, Network Rail, 2014.

[8] Morin G., BIM for the Subsurface. http://www.keynetix.com/bimforthesubsurface/, Innovate, UK, 2014.

[9] Suchocki M., BIM for Infrastructure; integrating spatial and model data for more efficient contextual planning, design, construction and operation. WIT BIM 2015: $1^{\text {st }}$ International Conference on Building Information Modelling (BIM), Bristol, UK, 2015.

[10] Bradner, et al., Parameters tell the design story: ideation and abstraction in design optimization. SimAUD 2014: Symposium on Simulation for Architecture and Urban Design, Tampa, USA, 2014.

[11] Benjamin, D., http://www.thelivingnewyork.com/, Columbia University, 2014.

[12] Mottle, J., http://www.cgarchitect.com/2016/02/2016-the-year-of-vr-stingray-andlive-design, CG Architect, 2016.

[13] Californian High Speed Rail Authority, Revised Business Plan, USA, 2012. 